DIVERSOS ASPECTOS PERSONALES Y SOCIALES EN LA PROCURACIÓN DE JUSTICIA EN MÉXICO

\author{
JORGE CARPIZO
}


I. PREOCUPACIONES Y PROPUESTAS SOBRE LA PROCURACIÓN DE JUSTICIA EN MÉXICO. II. LA PROCURACIÓN DE JUSTICIA EN EL CONTEXTO MORAL DE MÉXICO. III. EL FACTOR PERSONAL EN LA PROCURACIÓN DE JUSTICIA. IV. TIPOLOGÍA DE LOS PROCURADORES. V. LA RESPONSABILIDAD DE LA SOCIEDAD EN LA PROCURACIÓN DE JUSTICIA. VI. RECAPITULACIÓN*

* Agradezco a mis colegas Carlos F. Natarén Nandayapa y José Luis Ramos Rivera las sugerencias que realizaron a este ensayo. Los errores que puedan encontrarse en el mismo son responsabilidad exclusiva del autor. 


\title{
DIVERSOS ASPECTOS PERSONALES Y SOCIALES EN LA PROCURACIÓN DE JUSTICIA EN MÉXICO
}

POR

\author{
JORGE CARPIZO
}

Investigador emérito de la Universidad Nacional Autónoma de México*

Presidente del Instituto Iberoamericano de Derecho Constitucional

\section{PREOCUPACIONES Y PROPUESTAS SOBRE LA PROCURACIÓN DE JUSTICIA EN MÉXICO}

1. La procuración de justicia es una labor extraordinariamente delicada, porque implica a derechos humanos de especial relevancia como la libertad y diversos aspectos de la seguridad jurídica de las personas.

El tema del ministerio público, titular de la procuración de justicia, se centra sobre cuál debe ser su estructura y funciones en un moderno Estado democrático de derecho ${ }^{1}$. Entonces, es una cuestión relacionada con los límites del poder y las libertades públicas, así como con garantías individuales e, incluso, sociales.

El ejercicio de la acción penal es demasiado importante para los derechos humanos para dejarlo en las manos del poder ejecutivo ${ }^{2}$, y que pueda contaminarse

\footnotetext{
* Ex Rector de la misma Universidad, y ex Director del Instituto de Investigaciones Jurídicas, al que está adscrito como Investigador emérito.

${ }^{1}$ Díez-PiCAZO, Luis María, El poder de acusar. Ministerio Fiscal y Constitucionalismo, Barcelona, Ariel Derecho, 2000, pp. 12, 17 y 18, 109, 126, 133 y 134.

2 Hay D. y Snyder F. (eds.), Policing and prosecution in Britain, 1750-1850, Oxford, Gran Bretaña, Clarendon Press, 1989, p. 43.
} 
por causas políticas o partidistas. La imparcialidad y la objetividad del ministerio público son requisitos indispensables para asegurar la vigencia de diversos derechos humanos ${ }^{3}$.

La averiguación previa reviste especial importancia, en virtud de que puede restringir la libertad de los individuos e, incluso, si no se llega a ejercer la acción penal, dicha averiguación puede traer consigo consecuencias psíquicas, sociales y económicas para el afectadó .

A pesar de lo anterior, históricamente el ministerio público forma parte del poder ejecutivo o se encuentra cerca o influido por él. Son muy pocos los países en los cuales el ministerio público goza de real autonomía técnica, más allá de lo que prescriben las Constituciones y las leyes.

2. Por una razón u otra he estado cerca de la procuración de justicia en México, principalmente de la de carácter federal. Me consta que, en términos generales y con honrosas excepciones, los agentes del ministerio público y los de la policía de investigación laboran con incompetencia, falta de preparación, irresponsabilidad, carencia de compromiso jurídico, a base de consignas, a menudo con corrupción y desprecio a los derechos humanos. El panorama no puede ser más desolador y la víctima es la sociedad, la cual contribuye poco o nada a que aquél se modifique, tal y como expongo con posterioridad.

En tal virtud, el tema de la procuración de justicia me preocupa en especial y a él me he referido en varias ocasiones, tanto en mis acciones como en mis ensayos académicos, en mis testimonios e informes públicos al respecto.

En México, en este tema no se avanza, y cuando se logra dar pasos positivos, de inmediato aparece Atila para borrar por completo lo construido.

Las principales ocasiones en que he compartido con la sociedad mis preocupaciones y mis propuestas para superar este inmenso problema, que avasalla varios derechos humanos, primordialmente son las siguientes:

a) En 1990 resalté que la policía de investigación debía depender en la realidad del ministerio público, de acuerdo con la disposición constitucional; que la corrupción y la impunidad se podían comenzar a solucionar con medidas ejemplares; que era urgente la aplicación de la ley a quien incurra en actividades delictuosas - me refería en especial al delito de tortura-; que la falta de preparación de los policías era grave y urgía que recibieran ingresos decorosos; que la

3 Carpizo, Jorge, Propuestas sobre el Ministerio Público y la función de investigación de la Suprema Corte, México, Editorial Porrúa e Instituto Mexicano de Derecho Procesal Constitucional, 2005, pp. 2 y 3.

${ }^{4}$ Díez-PicAzo, Luis María, obra citada, nota 1, p. 11. 
discusión y la participación de la sociedad en dichos problemas era imperiosa, así como la necesidad de incidir en el terreno moral'

b) En 1994 recopilé los informes generales y especiales que rendí a la sociedad y al presidente de la República durante el año que tuve la responsabilidad de la Procuraduría General de la República: dos informes semestrales y la edición de informes sobre los casos más importantes que durante el año se habían determinado, los resultados de la lucha contra la corrupción y la impunidad con respeto a los derechos humanos; la creación de la carrera de los agentes del ministerio público y la de la policía judicial federal; la lucha frontal contra el crimen organizado; la creación de sistemas nacionales de información estadística sobre los más diversos aspectos de la procuración de justicia; la capacitación intensa a los agentes del ministerio público y de la policía de investigación; los estímulos económicos y sociales a dichos agentes si se distinguían en sus labores; la coordinación con las procuradurías estatales y las estrategias internacionales; los programas e involucramiento de organizaciones sociales en la prevención del delito, y la expedición de un Código de Ética para los servidores públicos de la dependencia ${ }^{6}$.

Parte de la filosofía con que se actuó en aquel año se sintetiza en el pensamiento de que una magnífica procuración de justicia es cien por ciento compatible con una magnífica protección y defensa de los derechos humanos, y que nadie se encuentra por encima de la ley ${ }^{7}$.

c) En 1998 insistí en los principios asentados en el párrafo anterior; entre otros aspectos, en el grave problema del aumento de la criminalidad; en la falta de continuidad en las políticas acertadas para combatir aquélla; en la preparación de los servidores públicos del área de procuración de justicia; en salarios dignos; en premiar a los agentes que se distingan por la calidad de su trabajo y honestidad, y en castigar a los incumplidos e infractores de la ley; en la utilización de las técnicas y tecnologías modernas para la investigación; en la importancia de los servicios periciales; en que no hay que perder el control de una corporación policíaca, porque después recuperarlo resulta en extremo complicado; y en la urgencia de que los agentes actúen con legalidad, eficacia, honestidad, responsabilidad y sentido de servicio a la comunidad ${ }^{8}$.

5 Carpizo, Jorge, Derechos Humanos y Ombudsman, 3. ${ }^{a}$ ed., México, Editorial Porrúa y UNAM. Instituto de Investigaciones Jurídicas, 2003, pp. 179-182.

${ }^{6}$ CARPIzo, Jorge, Un año en la procuración de justicia: 1993, México, Editorial Porrúa, 1994, pp. 27-100, 117 y 118, 155-162.

7 Ibidem, p. 98.

8 CARPIZO, Jorge, «Derechos humanos y procuración de justicia», en Nexos, México, 1998, número 251, pp. 13-15. 
d) En 2000 escribí sobre el problema de la honestidad en la Procuraduría General de la República (PGR) en una de sus vertientes: el manejo de los bienes asegurados a los presuntos delincuentes; bienes de los cuales antes de 1993 no existía ningún inventario ni a qué proceso estaban afectos; se presumía que algunos de esos bienes hubieran desaparecido; y precisé cómo en ese año se superó este inmenso problema, realizándose el inventario y entregándose copia del mismo a las dependencias federales fiscalizadoras, y la manera como se llevaron a cabo subastas públicas de los mismos ante notario público. Asimismo, me referí al deseable involucramiento de la sociedad en la procuración de justicia, y sobre la explicación clara y directa a la propia sociedad de las decisiones que se tienen que tomar dentro de los marcos de la Ley?

e) En 2002 realicé un diagnóstico del estado de la procuración de justicia en México, y entre otros aspectos, asenté:

La procuración de justicia se encuentra deteriorada y desprestigiada. La corrupción, la impunidad, la ineficacia, la improvisación, la irresponsabilidad y la hipocresía la han carcomido, como un cáncer que se apodera de todo el organismo. Estos males son bien representados por muchos servidores de esa área de la administración pública, y por los grandes delincuentes, pero también por organizaciones y líderes de los más diversos grupos sociales. Los problemas de la procuración de justicia no son únicamente responsabilidad de los servidores públicos —ojalá así fuera-, sino también de amplios sectores de la sociedad. La opinión pública se encuentra confundida, y no ha reaccionado a los pocos esfuerzos serios que se han iniciado para comenzar a suprimir esos males. En muchas ocasiones, se ha otorgado mayor crédito al ladrón que grita que se detenga al ladrón, que al funcionario probo que lucha desesperadamente por mejorar esa delicada e importante función pública.

Así, la procuración de justicia se ha convertido, en nuestro país, más allá de su dimensión jurídica, en una cuestión social y política, e incluso de seguridad nacional, en tanto el crimen organizado ha podido penetrar diversas estructuras del Estado y de la sociedad.

Después del breve diagnóstico sobre el estado de la procuración de justicia en México, dividí las reflexiones en tres apartados: i) los problemas derivados de las autoridades, y los agentes que aplican la ley, en los asuntos de la procuración de justicia; ii) los problemas que surgen por las actividades de organizaciones y líderes sociales, y iii) la manera como esos problemas pueden comenzar a superarse con base en experiencias concretas ${ }^{10}$.

9 CARPIZO, Jorge, Anatomía de perversidades. Reflexiones sobre la moral pública en México, México, Aguilar, 2000, pp. 55-58, 67-71.

10 Carpizo, Jorge, y Andrade, Julián, Asesinato de un cardenal. Ganancia de pescadores, México, Aguilar, 2002, pp. 515-537. 
f) El deterioro en la procuración federal de justicia durante el sexenio 2000-2006, principalmente durante los dos últimos de esos años, llegó a extremos increíbles, debido a una combinación de corrupción, incompetencia e irresponsabilidad, que es imputable no sólo a algunos de los funcionarios de la PGR, sino a la propia presidencia de la República, que intervino nombrando funcionarios y dando órdenes en esa dependencia.

Ante tal panorama, me percaté de que todas mis propuestas sobre la procuración de justicia continuaban siendo actuales y válidas, pero que eran insuficientes, que resultaba urgente una reforma de fondo.

Después de transcurridos cuatro años del mencionado sexenio, y ante mis preocupaciones e inquietudes que aumentaban ante la profundización de la crisis en la procuración de justicia, en 2004 y 2005 presenté a la consideración pública una propuesta para constituir a las procuradurías en órganos constitucionales autónomos, propuesta que integra una unidad y consta de seis aspectos que se imbrican:

i) La creación de un órgano constitucional autónomo.

ii) El nombramiento de los procuradores.

iii) La creación de los consejos del ministerio público y los de la policía. Las garantías de autonomía técnica a los agentes de esas organizaciones.

iv) La autonomía presupuestal.

v) La autonomía interna de los fiscales.

vi) El juez de control especializado en la averiguación previa ${ }^{11}$.

Fui claro que esta última propuesta no sustituye a las anteriores que había realizado, sino que las completa, y ésta es la más acabada y precisa de cuantas había hecho. Me referí con frecuencia al Derecho Comparado.

g) En 2006 examiné la supuesta conversión del ministerio público chiapaneco a un órgano constitucional autónomo para concluir que no es así. El nombre no determina la naturaleza de la institución, ni puede calificarse de tal por algunos aspectos aislados como es la intervención del Congreso en el nombramiento del entonces Procurador.

Asimismo, asenté que la propuesta de reforma del presidente Fox tampoco se dirigía en la dirección correcta ni se configuraría un órgano constitucional autónomo. Como ejemplo señalé la idea contenida en el proyecto de que la policía

${ }^{11}$ CARPIZO, Jorge, El expediente Posadas a través de la lupa jurídica. Averno de impunidades, México, UNAM-Instituto de Investigaciones Jurídicas, 2004, pp. 357-373. CARPIZO, Jorge, «El ministerio fiscal como órgano constitucional autónomo" en Revista de Estudios Políticos, Centro de Estudios Políticos y Constitucionales, Madrid, 2004, núm. 125, pp. 39-78. 
de investigación no dependiera del ministerio público, sino de una Secretaría de Estado $^{12}$. Curiosa concepción de la autonomía del ministerio público al suprimirle un elemento esencial para la investigación respectiva.

La concepción del ministerio público como órgano constitucional autónomo había ganado prestigio y adeptos en los ámbitos jurídicos, políticos y sociales ante la escalada de criminalidad que golpeaba y golpea a la sociedad. Las autoridades quisieron engañar haciendo propuestas que no eran lo que decían que proponían. Afortunadamente, el proyecto Fox se congeló en el Congreso de la Unión. Hubiera sido un retroceso en el campo, ya de por sí erosionado y muy minado, de la procuración de justicia.

\section{LA PROCURACIÓN DE JUSTICIA EN EL CONTEXTO MORAL DE MÉXICO}

1. Bien sabido es que las instituciones las hacen funcionar y las actualizan las personas, éstas son la sangre y la energía de aquéllas. Instituciones correctamente estructuradas no funcionan adecuadamente si en los cargos directivos se encuentran personas no idóneas. Cuando éstas son incompetentes, irresponsables, no comprometidas con su labor o corruptas, o una combinación de algunos o de todos estos aspectos, las mejores instituciones se encaminan al fracaso, el cual puede ser de proporciones mayores, si además se aúnan estructuras mal o débilmente concebidas.

La situación anterior resulta más grave si se inscribe en un clima social de desprecio a la ley, de tolerancia a la corrupción, de impunidad, de pérdida de valores morales laicos y de mentiras.

De esas cuestiones me he ocupado con anterioridad, y hoy regreso a ellas.

2. En mayo del año 2000 dibujé, a grandes trazos, algunos aspectos del sistema político mexicano y el panorama moral del país determinado por una quinteta de graves problemas: poder, dinero, corrupción, impunidad y mentiras.

Entonces afirmé, y en esta ocasión sólo recuerdo algunos párrafos, que:

El sistema político mexicano era examinado con curiosidad e interés por propios y extraños, cuando menos de 1940 a 1993, porque parecía un remanso de estabilidad, aunque ya contenía los gérmenes de su deterioro, en una América Latina convulsionada por frecuentes golpes de Estado. Este sistema po-

12 CARPIZO, Jorge, «El ministerio público chiapaneco como órgano constitucional autónomo» en Cuestiones Constitucionales. Revista Mexicana de Derecho Constitucional, México, UNAM-Instituto de Investigaciones Jurídicas, 2006, pp. 287-296. 
lítico giraba alrededor de dos ejes complementarios: un partido político hegemónico, cuyo jefe real era el presidente de la república, lo cual le permitía designar a gobernadores, legisladores federales y principales presidentes municipales. En esta forma, tenía en sus manos al Congreso de la Unión, en donde su partido, por décadas, controló en la Cámara de Diputados más del noventa por ciento de las curules, y en la de Senadores, el cien por ciento. El sistema federal se deterioraba porque los gobernadores eran casi funcionarios de confianza del presidente.

$\mathrm{Al}$ no tener ningún contrapeso en el Senado, el presidente nombraba con libertad a los ministros de la Suprema Corte de Justicia, y éstos aceptaban la sugerencia presidencial acerca de quién los debería encabezar. Sin embargo, el juicio de amparo alcanzó un alto grado de efectividad.

La vida política parecía que estaba cercana a la paz de los sepulcros, salvo cuando surgían fuertes disputas por el poder dentro del partido hegemónico, las cuales en varios sexenios pudieron casi diluirse, especialmente en los años en que el presidencialismo mexicano alcanzó su máximo esplendor.

Existieron brotes sociales de inconformidad, que fueron superados por la negociación, la cooptación o la represión. Fue un sistema astuto que supo cooptar a los opositores y críticos valiosos, encauzar y canalizar las inquietudes sociales; generalmente, con sus excepciones, fue exitoso en ambos aspectos.

Este sistema tuvo elementos positivos, como la estabilidad política, el crecimiento económico, un tinte social representado en aspectos como la educación pública gratuita, los derechos de los trabajadores, la reforma agraria, la seguridad social, la seguridad pública y un margen de libertades. Ese sistema no fue una dictadura ni un régimen totalitario. No obstante, tenía en sí los elementos de su propia destrucción, que se fueron agravando y, como un cáncer, extendiéndose en todo su organismo y en el propio cuerpo social.

La pobreza de amplios sectores no pudo ser superada; al contrario, hubo regresiones cuando la economía comenzó a perder su vigor y las crisis económicas recurrentes asolaron al país. La gran desigualdad social que siempre ha existido se profundizó; cada día los ricos fueron y son menos y más ricos, y los pobres más y más pobres.

La permanencia en el poder de un solo partido y el hecho de que la alternancia política no era una posibilidad cercana trajeron consigo corrupción e impunidad, enfermedades que, como no fueron detenidas, crecieron e invadieron todos los rincones del país. Desde el presidente de un municipio pequeño hasta el de la República, sabían que su sucesor — salvo pocas excepciones- los protegería como salvaguarda del sistema de partido político hegemónico: ésta era una de las reglas. 
La corrupción tenía y tiene un amplio margen de tolerancia social. Se robaba del presupuesto, pero más común era la realización de negocios aprovechándose del cargo; al dejar éste se tenía una fortuna chica, mediana o inmensa, según fuera el caso, pero no lícita; y quien lo hacía seguía siendo aceptado socialmente, incluso más, con la adición que otorga el dinero.

Hubo, y no hay duda alguna de ello, políticos honestos dentro del partido hegemónico; a quienes se solía considerar tontos, ya que no aprovechaban la oportunidad que se les presentaba. La corrupción fue permeando a otras capas sociales: los empresarios que hacían negocios con el gobierno, los dueños de los medios de comunicación que recibían "prebendas» y exención de obligaciones fiscales, los comunicadores que se beneficiaban con los conocidos «chayotes», los ministros de iglesias que recibían «limosnas» de origen dudoso, y todos con la no aplicación de la ley.

En otros niveles, líderes sindicales que aceptaban «regalos» de los patrones o que se convirtieron en grandes contratistas, ciudadanos que preferían dar una «mordida» al policía o al burócrata, que pagar una multa o realizar normalmente un trámite, jueces que fueron comprados por una de las partes en el juicio. La corrupción y la impunidad se fueron extendiendo y haciéndose cada vez más grandes: "puedo aprovechar la oportunidad que se me presenta, y qué, al fin de cuentas nada me pasará».

La corrupción y la impunidad continuaron avanzando; fueron invadiendo algunos de los estratos más altos de la política, del empresariado, de las finanzas, de los medios de comunicación e incluso de líderes religiosos.

En cualquier país del mundo en que un partido político permanece indefinidamente en el poder, se dan casos - más o menos graves, generalmente muy graves - de corrupción e impunidad. Entre los ejemplos más recientes, en los países desarrollados, encontramos los de Italia, Japón y la Unión Soviética. Luego, la situación de México no era peculiar del país, sino en virtud de que un poder que no posee contrapesos - y no tenía uno de los más importantes: la posibilidad de la alternancia en el poder derivada de la decisión de una elección libre- cae con más facilidad en los graves fenómenos de la corrupción y de la impunidad.

Los niños y los jóvenes nacieron y crecieron en este ambiente político y social, en el cual los dos valores más importantes y relacionados entre sí fueron y son: poder y dinero a como dé lugar y sin importar cómo se obtengan; lo único valioso es poseerlos, ya que ellos atraen todos los demás aspectos positivos de la existencia: felicidad, prestigio, reconocimiento.

Poder y dinero fueron y son compañeros de un tercer factor: la impunidad; se podía hacer casi de todo para adquirir poder y dinero y las posibilidades de 
que nada adverso aconteciera eran muy altas; en lugar de castigos, se obtendrían premios; peor ejemplo no podía existir para niños y jóvenes.

Nunca será acertado generalizar, pero la corrupción permeó y se apoderó de gran parte del sistema. Siempre hubo y hay gente honesta. A nadie se exigía responsabilidad alguna - perdón, quizá de vez en cuando al cartero o al oficinista: la impunidad pura y absoluta, a menos que un funcionario o autoridad importante hubiera caído de la gracia del señor presidente; entonces sí, todo el peso de la ley contra él, pero no como un acto de justicia, sino de venganza y de advertencia para los demás: se puede hacer todo lo que se quiera, menos molestar o disgustar al presidente, porque entonces sí se demostrará cómo se aplica la ley en el país: la espada de Damocles sobre el cuello del funcionario a la discreción del presidente.

El dinero y el poder como «valores supremos»; la mentira, el engaño, la simulación, como sus parientes cercanos o instrumentos necesarios para su obtención, y la impunidad como el manto protector de esos "valores»: éstos eran y son los que han permeado a grandes sectores sociales; éstos son los valores que han sido sembrados en muchos niños y jóvenes, quienes anhelan poseerlos. El éxito reflejado en quienes han obtenido poder y dinero sin importar los medios que han empleado; consideración y prestigio sociales para quienes escalaron la pirámide social y política, y representan esos «valores», sin importar sus biografías y sus ilícitos.

Esta atmósfera moral se vino a agravar por dos factores: por la impunidad que hizo cada vez más audaces a los delincuentes de cuello blanco - ial final nada le pasa a nadie! - y por el narcotráfico, el cual implica que pasan ríos de oro - decenas y cientos de millones de dólares - cerca o muy cerca de funcionarios públicos, empresarios, banqueros, comunicadores, jueces, sacerdotes, policías, y ya la opinión pública sabe — los casos aumentan- que muchos no resisten la tentación.

Existía en México — ¿existe todavía?-, una regla no escrita según la cual si una persona pertenecía a cierta dependencia y delinquía, había que ocultar el hecho para no desprestigiar a la institución; se le podía hasta separar del cargo, pero nada más; había que alejar a la dependencia del escándalo. Se pensaba que juzgar a un juez desprestigiaba al Poder Judicial, juzgar a un ministerio público deterioraba a la Procuraduría, juzgar a un sacerdote, lesionaba a su iglesia, juzgar a un comunicador erosionaba a toda la profesión y así hasta el infinito, la cultura de la impunidad y de las complicidades en todo su esplendor. Antes que nada, el prestigio de la institución, el prestigio muy mal entendido, pretextos para seguir reforzando la impunidad. 
Los casos de corrupción e impunidad llegaron a las más diversas y más prestigiadas instituciones del país; los ejemplos pueden señalarse al infinito, la total impunidad, pero todos se dicen inocentes y hacen gala de ello.

La mentira y el disimulo — ¿cinismo? - como parte del sistema. ¡Todos somos inocentes!: políticos, empresarios, banqueros, comunicadores, sacerdotes, líderes sindicales y sociales. ¡Todos somos inocentes! Todos lo pregonan y cada quien defiende su caso. Poder, dinero, corrupción, impunidad y mentiras: la quinteta de la muerte para México.

Los partidos políticos de oposición se fueron fortaleciendo. Los escándalos florecen - porque ya es imposible ocultarlos_-, la consolidación de una sociedad más crítica, alerta, cansada de tantos abusos, no ha podido detener el fenómeno de la corrupción ni disminuirlo, probablemente en algunos sectores haya aumentado, como todo lo relacionado con el narcotráfico, los contratos públicos y los rescates bancarios y de carreteras. La corrupción, como hidra de un millón de cabezas.

El problema de la corrupción no es un problema exclusivo del gobierno federal ni del entonces partido hegemónico, también ha prosperado en algunos gobiernos estatales y municipales a cargo de los más diversos partidos. En algunos casos, parece que la finalidad es: quítate tú para que entre yo, que ya me toca mi rebanada de pastel.

En México no se sabe a quién creer; algunos de los peores delincuentes que conozco quieren ser políticos en diversos partidos, comunicadores o líderes morales: la descomposición política, social y ética en grados inimaginables. El ladrón gritando «agarren al ladrón», y lo vocifera con tal seguridad, sangre fría y cinismo, que la sociedad ya no sabe a quién creer.

Poder, dinero, corrupción, impunidad y mentiras, es el ambiente moral dentro del cual han crecido nuestros niños y jóvenes; es el ejemplo que varias generaciones de mexicanos les hemos dado. Los jóvenes y niños quieren alcanzar en su existencia: poder y dinero a como dé lugar; además, y si son hábiles, inteligentes y bien relacionados, gozarán de impunidad. ¿Se puede querer o desear algo más? Empero, no todos sucumbieron a ese canto de sirenas y no se precipitaron contra las rocas de la indecencia y de la inmoralidad ${ }^{13}$.

3. En julio del año 2000, el Partido Acción Nacional ganó las elecciones presidenciales. Las expectativas fueron enormes desde los más diversos ángulos, más que la campaña del candidato presidencial ganador se basó, en gran parte, en la honestidad y en una lucha frontal contra la corrupción y la impunidad.

Debe asentarse que en ese momento, los entonces partidos políticos de oposición ya gobernaban en buena parte del país. Casi la mitad de la población

${ }^{13}$ Carpizo, Jorge, Anatomía de perversidades..., obra citada, nota 9, pp. 82-92. 
era gobernada en entidades federativas, Distrito Federal y municipios por partidos diferentes al entonces hegemónico ${ }^{14}$. Se escuchaban rumores de corrupción en algunos de esos gobiernos de oposición, pero no se presentaban pruebas. Es probable que la sociedad tampoco lo quisiera creer. Existían esperanzas y anhelos en la alternancia del poder a cualquier nivel de gobierno.

El sexenio del presidente Fox perdió la oportunidad de alcanzar la mayoría de las reformas que México necesita. Respecto a la quinteta apuntada: poder, dinero, corrupción, impunidad y mentiras no se avanzó nada o, incluso, se retrocedió. Como ejemplos paradigmáticos se pueden señalar los casos siguientes: Amigos de Fox, Pemexgate y el de sus hijastros ${ }^{15}$. Aún no se conoce la profundidad de la corrupción e impunidad de ese sexenio.

Cuando menos en la historia mexicana del siglo XX, nunca se había sorprendido a un presidente de la República mintiendo a todo el país en forma tan burda y que las pruebas no dejaban duda alguna. El presidente Fox declaró que no le había solicitado a Fidel Castro que abandonara la reunión de jefes de Estado de Monterrey. Pocos días después, todo México escuchó en la televisión la grabación en la cual Fox le decía a Castro que comiera y se fuera ${ }^{16}$.

Desgraciadamente el panorama moral descrito no responde únicamente al hecho de que un solo partido político haya gobernado el país durante casi setenta años. La enfermedad es más profunda y más difícil de superar, debido a que implica un grave problema social. Un cambio de mentalidad es lo más complicado y prolongado de alcanzarse.

Mi punto de vista debe quedar claro: en el análisis sobre la moral pública y la quinteta de la muerte que expuse en el año 2000, hice énfasis en la existencia del partido predominante. Hoy, en 2008, y después de contemplar que durante el primer sexenio de la alternancia en el poder, la quinteta de la muerte continuó gozando de la misma o mayor salud y energía que en las décadas anteriores, concluyo que el problema de la moral pública en México es más profundo y grave de lo que habia reseñado: en este aspecto los partidos politicos no se diferencian mucho uno del otro, y la sociedad es más tolerante en relación con esa quinteta de la muerte de lo que

${ }^{14}$ Lujambio, Alonso, El poder compartido, México, Océano, 2000, pp. 43-72 y 77-100. CASAR, María Amparo, La reforma política del Estado, México, Nostra ediciones, 2007, p. 22.

15 Córdova, Lorenzo y Murayama, Ciro, Elecciones, dinero y corrupción. Pemexgate y Amigos de Fox, México, ediciones Cal y Arena, 2006, 236 pp. Córdova, Lorenzo, «2000-2006: Claroscuros del Estado de Derecho», en ¿Qué país nos deja Fox?, SÁnCHEZ RebOlLEDO, Adolfo, compilador, México, Grupo editorial Norma, 2006, pp. 51-53.

${ }^{16}$ Debe anotarse que al respecto existe una versión que justifica al presidente Fox, y expone matices para tratar de aminorar la gravedad de este suceso. Véase AgUILAR V., Rubén y CASTAÑEDA, Jorge G., La diferencia. Radiografía de un sexenio, México, Grijalbo, 2007, pp. 161-170. 
parecía en los años anteriores. Hasta ahora la alternancia en la presidencia de la República no ha mostrado indicio alguno de que la situación tenga perspectivas de cambiar ${ }^{17}$, y lo mismo puede afirmarse en la mayoría de los Estados y municipios. Vuelvo a recordar que nunca será acertado generalizar, pero los casos de corrupción e impunidad que la opinión pública conoce en casi todos los rincones del país son realmente alarmantes.

Ahora bien, en este contexto transcurre la procuración de justicia del país, el cual se agrava con profundidad, cuando es precisamente el ministerio público federal el responsable de investigar y ejercer la acción penal en los delitos relacionados contra el crimen organizado, cuya capacidad de corromper es infinita, y la tolerancia de la sociedad hacia la corrupción es aún casi infinita.

\section{EL FACTOR PERSONAL EN LA PROCURACIÓN DE JUSTICIA}

1. Regreso a los aspectos personales en la procuración de justicia. Dentro de mis preocupaciones por mejorarla, ciertamente que no he descuidado esta cuestión.

Durante 1993 fue una de mis inquietudes constantes: lo que hicimos y los resultados alcanzados se encuentran en la memoria publicada al año siguiente ${ }^{18}$.

En 2002 me referí al inmenso problema que resulta encontrar a las personas idóneas para ocupar los cargos altos y medios en la procuración de justicia, que algunos de los mejores funcionarios en esa área han sido asesinados, y muchos de esos asesinatos continúan impunes ante la indiferencia de la sociedad; la corrupción de muchos altos mandos en las procuradurías y la comisión de proba-

${ }^{17}$ Aclaro que no me pronuncio todavía respecto al gobierno federal que tomó posesión el 10. de diciembre de 2006, en virtud de que aún el tiempo transcurrido es corto para hacer un juicio en este aspecto, y porque generalmente, la sociedad se entera de los casos cuando ha transcurrido más tiempo del sexenio, y difícilmente en los dos primeros años. Sólo adelanto que en la actualidad, la lucha contra el narcotráfico tiene una interrogación y es por demás complicado conocer o intuir como va a concluir. Respecto al problema de la impunidad sí destaco una situación que me preocupa: el presidente Felipe Calderón ha manifestado que el crimen organizado ha avanzado e incluso se ha apoderado de territorios en el país. Estoy de acuerdo con él. No obstante, esta situación aconteció y se agravó principalmente durante el sexenio federal 2000-2006, sin negar que este asunto proviene de antes. Pregunto ¿y de tal estado de cosas no hay ningún responsable?, ¿va a continuar el reino de la impunidad?, ¿fue el espíritu santo el que sacó de las cárceles de alta seguridad a criminales peligrosos?, ¿‘ue ese espíritu el que permitió el fortalecimiento de los cárteles del narcotráfico e incluso los protegió? hasta llegar a la situación que ha descrito el presidente Calderón.

18 CARPIZO, Jorge, Un año en la procuración de justicia: 1993, obra citada, nota 6, pp. 27-100. 
bles delitos al ejercerse esa función y el resultado es la impunidad total; mentiras y más mentiras y nada acontece, el litigio de casos judiciales en los medios de comunicación auspiciados o, de plano, inducidos por la autoridad. Asimismo, me referí a los problemas derivados de la actitud de líderes sociales en relación con la procuración de justicia ${ }^{19}$.

De varios de estos asuntos me ocupé en 1998 y en $2005^{20}$, aunque marginalmente.

No obstante, considero que, aunque en 2002 traté muchos de los principales problemas relacionados con los aspectos personales en la procuración de justicia, debo precisarlos y, en algunos temas, ampliarlos. Es lo que persigo en el presente ensayo desde dos ángulos, uno, una reflexión más integral de los aspectos personales de los servidores públicos en la procuración de justicia y, otro, la influencia negativa de diversas actitudes de líderes sociales y de la propia sociedad en la procuración de justicia.

2. El factor humano en el funcionamiento de las instituciones, específicamente en el campo de la justicia, es una cuestión conocida, aunque en México no abundan los estudios al respecto.

La última reflexión que conozco se debe a Andrés de la Oliva Santos, catedrático español de Derecho Procesal de la Universidad Complutense de Madrid, y quien a su inmensa obra escrita une la práctica cotidiana del litigio. El profesor hispano resume sus argumentos en los siguientes puntos:

1. El estado de la justicia no debiera examinarse, evaluarse y ser objeto de reforma sin otorgar la máxima relevancia al «factor humano» (magistrados, fiscales, secretarios judiciales, etcétera).

2. Ese "factor» responde en gran medida al estado de la sociedad.

3. El elemento humano de la justicia estará a la altura de sus cometidos si no nos conformamos con que sólo refleje el ambiente social, sino que procuremos que lo lidere y lo lidere ejemplarmente.

Con posterioridad reitera que:

1. La justicia de un país tiende a padecer los mismos males de la sociedad correspondiente.

2. Cualquier esfuerzo de reforma o de mejora de la justicia no puede hacerse ignorando la crisis de la sociedad, sus raíces y sus efectos.

19 Carpizo, Jorge y ANDrade, Julián, Asesinato de un cardenal..., obra citada, nota 10, pp. 517-530.

20 CARPIZO, Jorge, Derechos humanos y procuración de justicia, obra citada, nota 8, pp. 13-15. CarPIZO, Jorge, Propuestas sobre el Ministerio Público y..., obra citada, nota 3, p. XIV. 
No es razonable pretender que la administración de justicia, en una sociedad, rectifique todas, la mayoría o las principales consecuencias torcidas del desnortamiento social.

Y afirma:

No se trata de un mundo ante el que sólo quepa cruzarse de brazos, a la espera, poco esperanzada, de que otros («los demás») reaccionen y de que el «elemento humano» de la justicia mejore milagrosamente ${ }^{21}$.

Andrés de la Oliva se está refiriendo a la situación española de la justicia en sentido amplio, incluyendo a los fiscales, o sea a la procuración de justicia. Sus afirmaciones son válidas para México como para casi todos los países de este planeta. Estoy de acuerdo con su aseveración de que no es posible cruzarse de brazos a esperar que el elemento humano de la justicia mejore milagrosamente. Hay que actuar en esa dirección, y ello no se ha hecho ni se hace en México y, además, hacerlo en el rumbo correcto, en lo que tampoco hemos acertado. Nuestra brújula, en relación con la justicia, se encuentra enloquecida.

3. La procuración de justicia siempre ha sido una labor difícil, complicada y delicada. Es probable que en esta época lo sea más, en virtud de la existencia del crimen organizado. No es lo mismo enfrentar a un delincuente, un grupo o banda de delincuentes, que al crimen organizado que se ha globalizado, que obtiene ganancias que son verdaderos ríos de oro con los cuales participa en diversos sistemas financieros, en grandes empresas y medios de comunicación, que corrompe a servidores públicos, desde policías hasta miembros de gabinetes, altos oficiales de los ejércitos e interviene en campañas presidenciales, de legisladores y otros cargos de elección popular aportando fuertes cantidades de dinero. Los casos que conocemos en el contexto internacional, y que empezamos a vislumbrar en México, confirman las anteriores aseveraciones. En el sistema de justicia se corrompe desde agentes de la policía y del ministerio público hasta procuradores, desde jueces hasta magistrados.

El crimen organizado cuenta con sicarios entrenados militarmente, con armas de fuego de alto poder de las que carecen generalmente las policías, sistemas sofisticados de comunicación, información precisa de y sobre las autoridades y de sus movimientos para combatirlo. Además, amedrentan con su máxima de plata o plomo, que la hacen realidad.

Muchos buenos funcionarios de procuración de justicia y jueces han sido asesinados en diversos países del mundo y en México.

${ }^{21}$ Oliva SANTOS, Andrés de la, «El 'factor humano’ en la justicia (hablando claro sobre el tópico «justicia y sociedad»)» en Reforma Judicial. Revista Mexicana de Justicia, México, UNAM-Instituto de Investigaciones Jurídicas, 2007, núm. 10, pp. 27 y 28, 34 y 35. 
Hoy en día, el crimen organizado se concentra especialmente en el tráfico de estupefacientes, de armas, en redes de prostitución incluidos niños, de migrantes, secuestros y en juegos de azar. Es probable que en México los dos primeros rubros, especialmente el primero, sean el reto más grande para la procuración de justicia, aunque, en diversas y frecuentes ocasiones, aquellos se imbrican.

Entonces, queda claro que las personas responsables en estas funciones deben satisfacer una serie de requisitos. Las guerras no se enfrentan con generales impreparados, miedosos y vendidos al enemigo.

Los procuradores, subprocuradores, fiscales especiales, directores generales, jefes y comandantes de la policía de investigación no pueden ser improvisados y deben distinguirse por diversas cualidades, que son primordialmente las siguientes: a) preparación profesional, b) honestidad, c) valentía, d) convicción de que están prestando un servicio social al país, y e) equilibrio psicológico.

Entonces ¿se necesitan santos? No, sino mexicanos patriotas que cumplan con su responsabilidad, y quienes deben ser apoyados por la sociedad si desempeñan correctamente sus funciones. En caso contrario, la sociedad organizada debe denunciarlos e imponerle las sanciones que sí están a su alcance como sociedad, a lo cual me refiero con posterioridad.

Desde luego las cualidades que deben poseer los principales responsables de la procuración de justicia, toda proporción guardada, deben engalanar a todos aquellos que laboran en esas dependencias.

Respecto a dichas cualidades, suficiente se ha expresado y suficiente se ha escrito. No hay que agregar nada, únicamente que en la realidad los agentes del ministerio público y de la policía de investigación, en términos generales, se encuentran con una preparación deficiente, a pesar de que la Procuraduría General de la República cuenta con dos dependencias especializadas para su preparación: el Instituto de Capacitación y Profesionalización — paralizado en la actualidad-y el Instituto Nacional de Ciencias Penales, que hasta doctorados honoris causa confiere y que realiza «labor académica» brillante. ¿¿Dónde se encuentra la falla? Son cascarones para el oropel externo. Su fracaso se demuestra en que se gastan cantidades millonarias y los resultados positivos para la procuración de justicia son escasos.

Hablo de la cualidad, por ejemplo, de equilibrio psicológico. Se supone que la PGR realiza diversos exámenes antes del nombramiento de su personal, incluidos los altos puestos salvo el de Procurador General, para poder evaluar la personalidad de los candidatos. En 2002, la sociedad escuchó en los medios electrónicos la grabación de uno de esos exámenes a una candidata a subprocuradora que auspició, así lo admitió, la tortura de una persona con quien había tenido un problema personal, pero de todas maneras se le designó para el puesto. ¿̇Han ser- 
vido para algo los mencionados exámenes? Teatro puro, mentiras al por mayor. ¿Y la sociedad? Algunos sectores hasta compadecieron a la subprocuradora, alegando que se había violado su derecho a la intimidad al darse a conocer públicamente la grabación de ese examen. Incluso algunas personas preparadas y de buena fe la defendieron, sin comprender que un funcionario público tiene derecho a su vida privada, la cual es sagrada, a menos que afecte la función pública que realiza $^{22}$. Muchos no se percataron del grave peligro social que implica que un subprocurador sea, por lo menos, cómplice de torturadores. ¿Puede así transitarse a una mejor procuración de justicia? En ese caso, la responsabilidad no sólo fue de la "pareja presidencial» que apoyó y sostuvo a la subprocuradora en el cargo, sino también de amplios sectores sociales, incluidos algunos medios de comunicación.

Como puede contemplarse el problema es por demás delicado. En México, la procuración de justicia se complica en grado alarmante por: a) el contexto de la moral pública del país, al cual ya me referí, b) la corrupción que ha permitido el fortalecimiento del crimen organizado, c) en relación estrecha con lo anterior, las cantidades fabulosas de dinero que maneja dicho crimen organizado, especialmente el dedicado al narcotráfico, d) la impunidad, e) en términos generales los errados nombramientos en los altos cargos de la procuración de justicia, y f) la actitud y tolerancia sociales ante "la quinteta de la muerte» y el inmenso problema de la deficiente procuración de justicia.

\section{TIPOLOGÍA DE LOS PROCURADORES}

1. En una procuraduría general de justicia los cargos más importantes son: el procurador, los subprocuradores, el oficial mayor, los fiscales especiales, los coordinadores de área de los cuales suelen depender direcciones generales, y el director de la policía de investigación. En ocasiones, y dependiendo de la personalidad del procurador, otros cargos pueden tener relevancia como una específica dirección general, el visitador general o el coordinador de asesores.

De acuerdo con la realidad mexicana, y tomando en cuenta los últimos cuarenta años, intento realizar una tipología de procurador, que incluye tanto el de carácter federal como el local; tipología que puede hacerse extensiva a los principales funcionarios de la dependencia y, toda proporción guardada, en general, a todos los servidores públicos de esa área de la justicia.

22 CARPIZO, Jorge, El expediente Posadas a través de la lupa jurídica..., obra citada, nota 11, pp. 73-75 y 95-100. CARPIZO, Jorge, «Vida privada y función pública» en Derecho Comparado de la información, México, UNAM-Instituto de Investigaciones Jurídicas, 2004, núm. 3, pp. 61-71. 
El papel del procurador —y, desde luego, el de los subprocuradores-es esencial. Cuando se conoce que el procurador es capaz, honesto, valiente y justo, los colaboradores, por regla general, serán cuidadosos o más cuidadosos de no incurrir en actos de corrupción, de cumplir sus labores con responsabilidad y de evitar arbitrariedades $o$ violaciones legales. Por el contrario, cuando se conoce en la dependencia -y siempre se conoce porque hay formas de conocerse - que el procurador recibe sobornos, que generalmente son millonarios, que es arbitrario, que no tiene respeto a la ley, esas actitudes permean a los funcionarios, agentes y trabajadores de la institución; entonces, la procuración de justicia se convierte en un enjambre de complicidades.

Distingo cinco tipos de procuradores:

a) Honestos, con capacidad técnica y comprometidos con su responsabilidad. La honestidad es de carácter económico, pero también de actitud. No se aceptan regalos. No se utiliza el cargo para hacer relaciones públicas útiles para la persona. No se otorga prebenda alguna, como puede ser, a familiares, amigos o medios de comunicación. El presupuesto y el patrimonio de la institución se manejan correctamente. Hay inventario de los bienes asegurados y si se subastan, es en forma pública y de acuerdo con las normas.

Se trata de un jurista con preparación suficiente, especialmente en las ramas de Derecho Constitucional, Derecho Procesal Constitucional y Derecho Penal material y adjetivo. Se rodea de funcionarios capaces y con experiencia en procuración de justicia.

Encontrarse comprometido con su responsabilidad implica laboriosidad, largas jornadas de trabajo, que estudia los principales asuntos y decide de acuerdo con los marcos constitucionales y legales. Para él la única verdad legal es la que se encuentra en las pruebas jurídicas contenidas en el expediente. Es decir, no acepta indicaciones o consignas por razones de Estado o políticas. Si es necesario, está decidido a separarse del cargo antes que cometer una injusticia.

No se deja presionar por amenazas, poderes de hecho como grandes empresas, medios de comunicación o iglesias. Su estrella polar es únicamente la ley.

En la jungla que se han convertido las procuradurías de justicia, pareciera imposible que exista este tipo de procuradores. Pues sí han existido y, con posterioridad, me voy a referir a varios casos que me constan, y conozco otros más, tanto a nivel federal como local.

b) Honestos, con capacidad técnica, pero sin compromiso con su responsabilidad. En este tipo la diferencia con el anterior se encuentra en la tercera característica: el compromiso con la responsabilidad. El procurador decide no enterarse de lo que acontece en el país ni al interior de la procuraduría. Es la filosofía del dejar hacer, dejar pasar. No quiere comprometerse. No desea echarse encima enemigos de calibre ballena, que le harán la vida imposible tanto durante el desempeño del 
cargo, como puede ser con campañas negativas y constantes en los medios de comunicación, así como después que haya dejado el cargo, cuando incluso su vida corre peligro, tal y como tenemos ejemplos.

En la mayoría de los asuntos, incluso puede cuidar que se aplique la ley puntualmente, pero atiende instrucciones políticas o por razones de Estado y entonces subordina la ley a esas instrucciones. La filosofía de dejar pasar, dejar hacer es especialmente clara en relación con el narcotráfico, el poder político o los poderes de hecho.

En este tipo de procuradores suelen encontrarse personas cultas, agradables, con carisma. Pero han decidido no comprometerse con su labor. ¿Para qué? No existen estímulos sociales. Al contrario, conocen que su prestigio personal y profesional puede hundirse ante la batería constante de los ataques mediáticos, y que la sociedad no pondera ni apoya los esfuerzos por mejorar la procuración de justicia en beneficio de la propia sociedad y los derechos de las personas.

c) Honestos, sin capacidad técnica y sin compromiso con su responsabilidad. Este tipo es parecido al anterior; sin embargo, la diferencia se encuentra en que los procuradores carecen de capacidad técnica, son abogados mediocres o menos que mediocres, lo cual los vuelve inseguros en sus decisiones, e incluso en casos cotidianos no impera la ley, principalmente por falta de conocimientos jurídicos. No gozan del respeto profesional de sus subalternos. La procuraduría navega sin capitán.

d) Corruptos, con capacidad técnica y sin compromiso con su responsabilidad. La corrupción los lleva de la mano a menospreciar su responsabilidad con la ley y la sociedad.

Un procurador federal corrupto, en razón del narcotráfico, puede llegar a recibir millones de dólares al mes. Para tener una idea clara al respecto, me refiero al caso de un comandante, uno de los más importantes en su época: Guillermo González Calderoni. La DEA (Drug Enforcement Administration, Agencia Antidrogas) calculaba su fortuna en cuatrocientos millones de dólares. Lo que a la Procuraduría General de la República le constaba, cuando lo consignó en 1993, es que sus bienes no correspondían a sus remuneraciones; entre aquellos se encontraban cinco magníficos inmuebles, una compañía de autotransportes, una flotilla de cien trailers o tractocamiones, ranchos, quinientas cabezas de ganado fino.

En varias ocasiones he afirmado que la mano que roba se puede ocultar; no la que gasta. La ostentación principesca en que viven varios ex-procuradores, por decir lo menos, no deja de extrañar.

Como es fácil de entender se puede ser corrupto y sin compromiso con la responsabilidad, pero gozar de capacidad técnica y estar profesionalmente preparado para el cargo. 
Así hemos visto casos en que un procurador obtiene triunfos en la lucha contra el narcotráfico, los cuales son reconocidos nacional e internacionalmente. Esos triunfos se deben a que conoce como realizar su trabajo, pero sólo golpea a un cartel y apoya al otro, el cual lo compensa con cataratas de billetes verdes, en virtud de que no sólo los protege sino que debilita a su competencia. Así se cierra un círculo infernal.

e) Corruptos, sin capacidad técnica y sin compromiso con su responsabilidad. Así han proliferado procuradores, y después del cargo, la impunidad y la red de complicidades los han protegido.

2. ¿Por qué para muchas personas esos cargos son tan apetecibles? Por las siguientes razones, ya sea por una, varias o todas:

a) El dinero puede llegar con facilidad y en cantidades inimaginables. Recordemos que en la atmósfera moral de México, aquél es uno de los valores más apreciados.

b) El poder. No cabe duda alguna que quien determina el ejercicio de la acción penal, y más con amplio margen de discrecionalidad, goza de un gran poder, al estar determinando incluso la libertad de las personas. Además, cuenta con fuerza física al ser el jefe último de la policía de investigación, cuyos agentes dependen de él y generalmente no gozan de ninguna garantía de estabilidad en el puesto. En consecuencia, difícilmente encuentra oposición incluso a sus decisiones más arbitrarias y antijurídicas.

c) Promoción personal. Tiene los reflectores del país o de su Estado sobre él. Dispone de recursos económicos enormes para promoverse en los medios de comunicación, con algunos de los cuales hasta alianzas suele construir. Alguien desconocido puede en unos meses forjarse una personalidad mediática, aunque los resultados de su actividad sean magros. Hay incluso procuradores que pensaron que el cargo los conduciría a la presidencia de la República, y con tal fin utilizaron todos los instrumentos, y de toda naturaleza, de la dependencia.

d) Relaciones públicas tanto nacionales como internacionales. En ese cargo puede dedicarse a cultivar relaciones con lo más granado del empresariado, del medio intelectual, académico y religioso, así como con altos funcionarios de Estados Unidos, América Latina y Europa.

e) El convencimiento, basado en la realidad de que, haga lo que haga, gozará de impunidad. Entonces, el cargo se vuelve más apetecible, jugoso y deseable. 
3. ¿Cómo lograr que los funcionarios de la procuración de justicia sean los adecuados? Es decir, que respondan al tipo de procurador honesto, con capacidad técnica y comprometido con su responsabilidad?

Externo unas ideas:

a) El nombramiento del procurador no lo debe realizar el poder ejecutivo, sino que a nivel federal debe quedar en manos del Senado, órgano que lo designaría, por las dos terceras partes de los legisladores presentes, de una cuarteta, dos nombres los propondría el pleno de la Suprema Corte y dos el pleno del Consejo del Ministerio Público.

b) Amplio análisis e investigación de los curricula de los cuatro propuestos con la finalidad de cerciorarse de que reúnen las cualidades para el cargo: honestidad, capacidad técnica, responsabilidad, compromiso. La comisión respectiva del Senado llevaría a cabo comparecencias públicas de los candidatos $^{23}$.

c) La creación de los Consejos del Ministerio Público y los de la policía de investigación, que serían órganos con integración y funciones similares a las de los Consejos de la Judicatura. Es decir, su finalidad más importante sería la administración y supervisión tanto de la carrera ministerial como la de la policía, así como la garantía de independencia técnica de esos agentes ${ }^{24}$.

d) La creación de una verdadera carrera de agente del ministerio público y de agente de la policía de investigación. Lo que hoy existe es una farsa. El intento serio para crear dicha carrera fue destrozado por completo.

e) Cero impunidad para los servidores públicos de las procuradurías de justicia.

f) Verdadera capacitación técnica. La actual es deficiente. Hay que acabar con la simulación. México no necesita prioritariamente agentes «con doctorados", sino bien preparados desde el aspecto técnico.

g) Seriedad en los exámenes de ingreso, tanto de carácter técnico como psicológico. Los que hoy en día se realizan responden más a razones po-

23 Carpizo, Jorge, Propuestas sobre el Ministerio Público y..., obra citada, nota 3, pp. 36-37.

${ }_{24}$ Ibidem, pp. 37-41. Véanse GIACOBBE, Giovanni, «Autogobierno de la Magistratura y la unidad de la jurisdicción en el ordenamiento constitucional de la República italiana», en Justicia y sociedad, México, UNAM-Instituto de Investigaciones Jurídicas, 1994, p. 103. FIX-ZAMUDIO, Héctor, "Órganos de dirección y administración de los tribunales en los ordenamientos latinoamericanos» en Memoria de El Colegio Nacional, México, El Colegio Nacional, 1992, pp. 43-44. Del mismo autor Los problemas contemporáneos del Poder Judicial, México, UNAM-Instituto de Investigaciones Jurídicas, 1986, pp. 37-40. 
líticas o de favoritismo. Baste sólo el ejemplo de la subprocuradora, al que ya me referí, que ordenó la tortura de una persona con quien tuvo un pequeño accidente de tránsito, o cuando menos fue cómplice de esa tortura y, sin ningún reparo, fue designada.

h) Estímulos sociales y económicos a los funcionarios cumplidos, y premios a los que logren resultados sobresalientes.

i) A los principales funcionarios otorgarles una época de protección al finalizar sus cargos, protección que se puede prorrogar de acuerdo con las circunstancias.

A nadie se le puede exigir que sea un héroe. Si la sociedad y el Estado quieren, y en mi criterio lo necesitan con urgencia, procuradores honestos, con capacidad técnica y comprometidos con su responsabilidad, es indispensable que creen las condiciones para ello, la primera es la seguridad personal para el funcionario y su familia después del cargo. Estas salvaguardias tienen que ser de carácter institucional y no como prebendas otorgadas por los siguientes funcionarios, o que se concedan o no con base en consideraciones políticas.

j) Como regla general, es preferible que a los altos cargos del ministerio público no asciendan personas muy jóvenes, para que cuenten con amplia experiencia profesional y mejor comprensión de la realidad y de la existencia. Desde luego que existen excepciones. Conozco a jóvenes que desempeñaron su labor muy bien e incluso en forma excelente.

\section{LA RESPONSABILIDAD DE LA SOCIEDAD EN LA PROCURACIÓN DE JUSTICIA}

1. En términos generales el fracaso de la procuración de justicia aflige a la sociedad. Estupefacta contempla cómo aumenta el número de asesinatos, secuestros, decapitados, enfrentamientos con armas de alto poder en las vías públicas.

En la cuarta encuesta nacional sobre inseguridad urbana, realizada en 16 zonas de alta incidencia delictiva, durante 2005 , el $71.1 \%$ de los ciudadanos entrevistados manifestó que se siente inseguro en la entidad federativa en donde habita, $57 \%$ en relación con su municipio y $72.5 \%$ en la ciudad en que vive. $46.8 \%$ declaró que consideraba que los delitos se habían incrementado en su municipio o delegación durante 2005. 13.5 de cada 100 personas expresaron que la inseguridad había afectado de manera considerable su nivel de vida, 36.6 dijeron que únicamente un poco y 47.1 que nada. Cuando se les interrogó 
si habían dejado de hacer algo debido al temor de ser agredidos por delincuentes, se contestó en orden decreciente que sí en los siguientes rubros: más del 50\% en usar joyas; salir de noche; llevar dinero en efectivo; tomar taxi; visitar parientes o amigos; usar transporte público; traer tarjetas de crédito; ir al cine o al teatro; salir a comer o cenar, hasta ir al estadio en un $18 \%$.

Asimismo, los encuestados han tomado acciones para protegerse de la criminalidad, tales como, de más a menos, colocar cerraduras, poner rejas o bardas, medidas conjuntas con los vecinos, tener perro guardián, aumentar seguridad para auto, vigilancia privada para la calle o la colonia, colocar alarmas o contratar seguro para la casa o el negocio.

En relación con la confianza, satisfacción y calificación que les merecen los cuerpos de seguridad pública, el promedio, en una escala de 0 a 10 , fue el siguiente: Agencia Federal de Investigación 5.5, Policía Judicial Estatal 4.1, Agentes del Ministerio Público 4.2, Policía de Tránsito 3.7. Las cifras anteriores indican con claridad la percepción social respecto a este grave problema ${ }^{25}$.

Veamos algunas cifras sobre seguridad y delincuencia en un lapso de treinta años:

a) Presuntos delincuentes del fuero común y fuero federal registrados en juzgados de primera instancia en materia penal, por cada 100 mil habitantes. En 1977: 133. En 2006: 200.

b) Delincuentes sentenciados del fuero común y fuero federal, por cada 100 mil habitantes. En 1977: 96. En 2006: 156.

c) 3.1 fue la tasa de crecimiento anual de presuntos delincuentes del fuero común relacionados con delitos de homicidio, lesiones y robo entre 1977 y 2006.

d) 3.4 fue la tasa de crecimiento anual de delincuentes sentenciados del fuero común relacionados con delitos de homicidio, lesiones y robos entre 1977 y 2006.

e) 4.7 fue la tasa de crecimiento anual de los delincuentes sentenciados del fuero federal por delitos de homicidio, lesiones, robo y delitos contra la salud entre 1977 y 2006.

f) 5.4 fue la tasa de crecimiento de los delincuentes sentenciados del fuero federal por delitos contra la salud entre 1977 y 2006.

g) 18.6 pesos se gastaron (a precios de 2007) por habitante por la Procuraduría General de la República en 1980.

25 Cuarta encuesta nacional sobre inseguridad urbana, México, Instituto ciudadano de estudios sobre la inseguridad, a.c., Instituto Nacional de Salud Pública, 2006 ENSI-4 Urbana, 2007, pp. 53-59. 
h) 87.8 pesos se gastaron (a precios de 2007) por habitante y por la misma dependencia en 2006. Es decir, más de cuatro veces, ¿y los resultados?26.

De los datos anteriores se desprende con claridad el aumento imparable de la delincuencia, salvo en algunos periodos, que por lo general no han sido prolongados, pero principalmente son en los últimos años cuando los índices delictivos se disparan, que es cuando las procuradurías han contado con más recursos económicos. Como se desprende de los dos párrafos anteriores, sólo en la PGR en esos treinta años, el presupuesto aumentó más de cuatro y media veces. Reitero mi pregunta ¿y los resultados? La inseguridad y la delincuencia en materia federal creció - mi estimación está basada en los anteriores incisos e) y f) —, en el primer caso $397 \%$ y en el segundo, $484 \%$, en dicho lapso de 30 años. Acepto que son cálculos que pueden tener márgenes de error.

2. Es obvio que la mayor responsabilidad del desastre nacional en seguridad y en la lucha contra la delincuencia corresponde a los tres niveles de gobierno y, en particular, a la Procuraduría General de la República, a las Procuradurías de las entidades federativas y del Distrito Federal, y a las diversas corporaciones de policía que existen en el país.

No obstante, la responsabilidad que en dicho desastre corresponde a la sociedad no es menor, debido a que, aunque sufre las consecuencias del desastre, no contribuye a superarlo y, en ocasiones, sí a empeorarlo. Esta aseveración la fundamento en los siguientes argumentos:

a) Algunos de los mejores funcionarios de procuración de justicia han sido asesinados y esos crímenes continúan impunes. La sociedad se muestra desinteresada y apática para exigir que se investiguen. Casi ninguna organización social o persona lo han hecho, lo cual resulta grave porque aleja de esos cargos a gente idónea para ocuparlos.

A Leobardo Larios Guzmán, procurador general de justicia de Jalisco, le correspondió la co-responsabilidad de investigar el asesinato del cardenal Posadas. «La Rana», uno de los jefes de los sicarios del cartel agresor, le solicitó que integrara mal las averiguaciones previas de ese caso para que los jueces se vieran obligados a decretar la libertad de sus sicarios detenidos. Larios Guzmán se negó. Al término de su gestión como procurador, el gobierno siguiente le suprimió de inmediato la escolta que lo protegía. Poco tiempo después fue asesinado por miembros del grupo de «La Rana». Tal acto no tuvo ninguna consecuencia política o social para el gobernador y procurador entrantes. Cuando «La Rana» fue

${ }^{26}$ López Portillo, Ernesto, «Seguridad y delincuencia» en Nexos, México, 2008, núm. 361, p. 69.

(C) UNED. Revista de Derecho Político

N. ${ }^{\circ}$ 74, enero-abril 2009, págs. 507-537

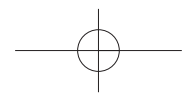


detenido años después, personajes de ese Estado como el cardenal Sandoval Iñiguez y el actual Secretario General de Gobierno Fernando Guzmán lo visitaron en varias ocasiones en la cárcel. Ante todo ello no existió ninguna reacción social. $\mathrm{Al}$ contrario, ambos visitantes continúan siendo grandes personajes en el Estado, a pesar de que Guadalajara se había convertido en uno de los bastiones del narcotráfico.

Juan Pablo de Tavira fue el responsable de las cárceles de alta seguridad en el país. A él no se le escapó ningún preso de ellas. Con posterioridad se desempeñó como director general de la ex-policía judicial federal. Ocupaba ese cargo cuando se intentó asesinarlo abriendo las llaves del gas de su domicilio. Casi lo logran. Estuvo muy grave y nunca se recuperó por completo. Cuando ya se encontraba separado del cargo, en la cafetería de una Universidad, un sicario se acercó y, con precisión profesional, de un tiro lo ajustició. Muy pocas voces se escuchan solicitando que ese crimen cometido hace años no quede impune. Nada. Voces en el desierto y eso que Tavira es padre de varios nietos de uno de los empresarios más ricos e influyentes del país. El mensaje para los funcionarios honestos, eficaces, responsables y comprometidos del sector no puede ser peor. De nueva cuenta, la sociedad se muestra indiferente ante la impunidad. ¿Es que no comprende que con ello se inflige un daño tremendo a sí misma al propiciar el crecimiento de la inseguridad y del crimen? y que las personas idóneas se alejen de dichas responsabilidades.

Los casos abundan: otro más, el asesinato de Abraham Polo Uscanga, subprocurador en el Distrito Federal. No se supo, no se sabe, nada de nada.

A Francisco Rodolfo Álvarez Farber, ex-procurador de Sinaloa, lo asesinaron por órdenes instruidas desde una cárcel de alta seguridad por un ex-comandante judicial ligado al narcotráfico. Su caso sí fue esclarecido y el autor intelectual así como los materiales fueron consignados. La honestidad de Álvarez Farber, además de la eficacia y compromiso con su responsabilidad, se encuentra a prueba de toda sospecha.

b) Ex-funcionarios de la procuración de justicia que se enriquecieron en forma increíble y cuyo tren de vida muestra su gran fortuna, son aceptados y bien recibidos en todas partes y pertenecen a la élite social. Son por su dinero y poder grandes señores. Reacción social negativa, cero. Aceptación total, aun de personajes que bien conocen quienes son aquellos y el origen de su fortuna. La sociedad no tiene memoria o la tiene sólo para honrar a quien acumuló una fortuna, sin importar el origen de ésta.

c) En los tres últimos sexenios han existido subprocuradores que, además de corruptos, cometieron probables delitos. Uno fue notorio por el ordenamiento de torturas y encubridor de crímenes. Otro, involucró a los dirigentes de un par- 
tido político y a su propio jefe, el procurador, sin prueba alguna, en el asesinato de su hermano, y aprovechó la tragedia para obtener beneficios personales. La sociedad y algunos partidos políticos, uno incluso lo designó su asesor jurídico, lo convirtieron en héroe civil hasta que se le descubrió una fortuna inexplicable ${ }^{27}$, que el gobierno exhibió.

Uno más consignó a un culpable que él fabricó, pagó testigos, inventó pruebas. Cuando entraba a un restaurante, los comensales llegaron a aplaudirlo, su popularidad le hizo creer que incluso podía llegar a la presidencia de la República.

Otro más, siguió el ejemplo, fabricó pruebas, engañó, mintió incluso que sus hijos habían sido amenazados y sufrido accidentes para ganarse el apoyo de la opinión pública, la cual conoció que se trataba de patrañas y, en general, no reaccionó.

En todos estos casos, al principio, la sociedad no sólo los apoyó, sino los impulsó. Con posterioridad, al conocerse la verdad y desilusionarse, se cargó todo el costo a la procuración de justicia, sin que la sociedad aceptara ninguna responsabilidad para ella.

d) Algunas organizaciones no-gubernamentales, por filias o fobias, otras por corrupción, han mantenido campañas de desprestigio contra funcionarios honestos, probos y eficaces. Las organizaciones no-gubernamentales serias han decidido hacerse a un lado en estos casos. Ninguna denuncia; al contrario, aceptación de la organización fachada.

Un solo ejemplo basta: un periodista de Tamaulipas creó una organización no-gubernamental, cuya finalidad real fue la defensa de narcotraficantes. Cuando el ya mencionado ex-comandante Guillermo González Calderoni, el de la fortuna de los cuatrocientos millones de dólares según la DEA, era prófugo de la justicia mexicana, y residía en Estados Unidos, el periodista tamaulipeco se responsabilizó de la defensa del prófugo con sus colegas, incluso invitándolos, con todos los gastos pagados, claro está, a que escucharan personalmente la versión de González Calderoni sobre «su inocencia».

Muchas organizaciones no-gubernamentales serias conocieron esta situación, nunca la denunciaron y continuaron relaciones con el periodista tamaulipeco y su organización como si fueran respetables.

e) Algunos medios de comunicación se prestan voluntaria o involuntariamente a campañas atroces para desprestigiar al funcionario capaz y probo. La finalidad es hacerlo flaquear en sus principios. Generalmente detrás de estas campañas existen intereses económicos fuertes para las empresas o para algunos comunicadores.

${ }^{27}$ CARPIZO, Jorge, Anatomía de perversidades..., obra citada, nota 9, pp. 98-102. 
La sociedad, en diversas ocasiones, se percata de que el comunicador miente, hace de la mentira una práctica, y no recibe ninguna sanción por parte de la opinión pública cuando los hechos posteriores muestran y vuelven a mostrar que ha mentido deliberadamente, se le continúa escuchando o leyendo como si se tratara de un comunicador veraz y objetivo ${ }^{28}$.

Algunos medios de comunicación y algunos comunicadores han sido comprados por diversos cárteles del narcotráfico ${ }^{29}$; hoy en día, ésta es una afirmación que proviene de los propios medios de comunicación y de comunicadores con alto sentido ético de la existencia y de su profesión, y de los mismos narcotraficantes, como la declaración que hizo Benjamín Arellano Félix, aunque atribuyendo este hecho a "el chapo Guzmán ${ }^{30}$, en el sentido de que éste era muy poderoso, porque compraba todo, que incluso pagaba periódicos, y el propio «chapo Guzmán» acusó de lo mismo a los jefes del cártel de Tijuana. Resulta increíble que algunos medios electrónicos concedan espacios privilegiados, y por tiempos prolongados, a verdaderos gángsteres que han ofendido gravemente a la sociedad, les permiten «defenderse» y atacar a quienes les han aplicado la ley; los tiempos que les conceden son especialmente prolongados.

Ahora bien, hay medios de comunicación que no han contribuido a fortalecer una buena procuración de justicia, y están lejos de tener vínculo alguno con el narcotráfico; lo que sucede es que la noticia que se vende es la escandalosa, la que llama la atención, la que tiene contenido morboso, y la competencia entre los medios es muy dura; la lucha por conseguir patrocinadores y clientes no tiene tregua, ni cuartel. Por todo ello, hay que realizar un reconocimiento a los medios y a los comunicadores que actúan con sentido ético de la delicada función que ejercen.

f) La sociedad no tiene memoria, se le engaña y se le vuelve a engañar y no reacciona.

Líderes políticos, sociales y religiosos mienten sobre casos de procuración de justicia, además de que gozan de impunidad, no reciben sanción social alguna, aunque para grandes sectores de la sociedad es claro que tratan de manipular casos sensibles de la procuración de justicia en beneficio propio o de su grupo.

${ }^{28}$ CARPIZO, Jorge, y ANDRADE, Julián, Asesinato de un cardenal..., obra citada, nota 10, pp. 524-528. CARPIZO, Jorge, Un año en la procuración de justicia: 1993, obra citada, nota 6, pp. 446453.

29 Véase la declaración de Carlos Payán Velver en El Universal del 22 de mayo de 2001, p. A8. Consúltense algunos aspectos de la corrupción en los medios, en La Jornada del 24 de mayo de 2001, p. 7, y en Trejo Delarbre, Raúl, Volver a los medios. De la crítica a la ética, México, Ediciones Cal y Arena, 1997, 389 pp.

${ }^{30}$ Véase Excelsior del 28 de julio de 1994, pp. 1 y 28. 
También, ocurren declaraciones de otros líderes que no persiguen intereses propios, sino responden a una gran irresponsabilidad, declarando lo primero que pasa por su mente, sin conocer el asunto, y no hacen ningún esfuerzo de informarse.

g) En ocasiones, la sociedad exige resultados inmediatos de las investigaciones. A veces, es posible proporcionarlos, porque ya se tienen, en otras no. En diversas ocasiones, la presión para el otorgamiento de información ha perseguido la finalidad de alterar o desviar la averiguación previa.

Se ha llegado incluso al caso de que si con prontitud se proporciona información, porque la investigación lo permite, se especula que existe precipitación en la noticia, debido a que se quiere ocultar la verdad, pero si la información no se otorga, se supone que es por la misma razón. El absurdo del absurdo.

h) Muchos actores políticos discuten y cuestionan los casos más importantes de la procuración de justicia, con el objeto de obtener ganancias políticas y sociales y golpear al antagonista, sin importarles si sus alegatos gozan de algún sustento.

Situación diferente es si la procuración de justicia es deficiente o se comete una injusticia, porque entonces hay que dar la batalla contra esas deficiencias o vicios y conseguir el pleno respeto de los derechos humanos. En estos casos, la denuncia y el seguimiento de los expedientes por parte de la sociedad, los medios y las fuerzas políticas, son indispensables.

Con la politización de la justicia casi nadie gana; desde luego, no la sociedad. No obstante, algunas corrientes ideológicas y políticas — como la ultraderecha- han manipulado casos, con la finalidad de obtener votos, y debe admitirse que su estrategia les ha resultado exitosa.

i) En sociedades regionales, incluso en algunas de las más conservadoras y cerradas, llegan personas desconocidas, nadie sabe quienes son, pero poseen fortunas inmensas, comienzan a comprar algunas de las mejores residencias del lugar a precios sobrevaluados que los dueños no resisten, a invertir en grandes empresas prestigiadas, a realizar donaciones inmensas para obras de beneficencia, religiosas o culturales. Se relacionan con la élite social y económica del lugar cuyos miembros asisten a sus fiestas versallescas. Se van estableciendo relaciones de amistad que, a veces, terminan en familiares a través de bodas.

No se sabe de dónde provienen esas personas ni el origen de su colosal fortuna. No se quiere saber. No se indaga. No se comenta aunque se presiente que pueden estar relacionadas con el crimen organizado.

En ciudades pequeñas, jerarcas del crimen organizado regalan escuelas, iglesias, hospitales. Se conoce quiénes son y cuál es su actividad, pero son bienes necesarios para la colectividad y se aceptan. Es más, en algunos casos, esos jerarcas 
gozan de simpatía social. En mi opinión, estas situaciones son socialmente menos dañinas que la hipocresía de las «buenas sociedades» santonas y cínicas.

j) En el clima moral de México, al cual ya me referí, muchos niños y jóvenes ven su incursión en el crimen organizado como un camino aceptable para alcanzar los verdaderos valores de la sociedad mexicana, debido a que si adquieren poder y dinero, obtendrán impunidad y prestigio social.

k) La situación ha llegado a extremos inconcebibles y la sociedad ni sus organizaciones reaccionan. Procuradores honestos y eficaces que lograron éxitos contra el crimen organizado, cuando finalizan el cargo, son llamados por jueces en calidad de testigos o para carearlos con los delincuentes a los cuales consignó, y se le piden públicamente sus datos personales como el domicilio, exponiéndose a su familia. La comparecencia del ex-procurador no es necesaria en el juicio; al realizarse se amedrenta a los procuradores. Como dijo un ex-procurador: «iEntonces cuál seguridad se tiene en el cargo!» y más cuando es claro que se trata únicamente de una medida dilatoria en el juicio o de una presión política para que alguien salga de la cárcel ${ }^{31}$.

Los medios de comunicación difundieron esa situación y nadie protestó, ninguna asociación de abogados. Nadie. A nadie le importó.

l) No puedo ignorar que en muchas ciudades, la sociedad sufre una gran frustración, debido a que se presenta la denuncia penal y nada acontece, lo cual estimula el temor y la desconfianza. Cuando la sociedad cumple su parte y denuncia algo extraño o sospechoso, debe observar una reacción contundente de la autoridad; en caso contrario, el desaliento se convierte en sospecha y después en miedo.

3. La procuración de justicia no va a mejorar sensiblemente y de fondo, si la sociedad no se involucra en el problema y comienza a modificar muchas de las actitudes anteriormente descritas. Enuncio algunas ideas que pueden ayudar a regenerar la procuración de justicia y que corresponden a la sociedad:

a) Con acciones ir cambiando la moral pública de México. Lucha frontal, no aceptación y repudio real a la quinteta de la muerte, a la cual me he referido en este ensayo y en otras ocasiones.

b) Exigir a la autoridad impunidad cero, se trate de quien se trate, así sea un dirigente político, social o religioso muy poderoso.

c) Repudio social a los delincuentes, especialmente a quienes al ocupar un cargo público se enriquecieron ilícitamente, y a quienes actuaron fuera de la Ley.

31 Entrevista al ex-procurador Alfonso Navarrete Prida en El Sol de México del 30 de agosto de 2007 , pp. 1 y $2 \mathrm{~A}-4 \mathrm{~A}$. 
d) Cuidado en las organizaciones sociales para no proteger a delincuentes o a quienes los defienden.

e) El acatamiento de las normas éticas de la profesión periodística para proporcionar información objetiva, verificando las fuentes, no reproduciendo chismes ni mentiras, ni haciéndose eco de intereses lejanos a la verdad. Los medios deben realizar periodismo de investigación, denunciar cualquier irregularidad y probable delito.

En la procuración de justicia, tan importante es la denuncia pública con fundamento, como la lucha contra las mentiras y los infundios.

f) La sociedad tiene que poseer memoria de los casos paradigmáticos a través de informarse bien para no dejarse engañar por funcionarios públicos, ex-funcionarios públicos o líderes sociales y religiosos.

g) Evitar que la procuración de justicia se politice, eludiendo que los casos jurídicos se utilicen con fines políticos.

h) Rechazo social a quienes tienen fortunas inexplicables o que bien se conoce que su procedencia es el crimen organizado, mucho menos recibir alguna prestación económica, servicio o colaboración por parte de ellos.

i) Presión social para que los crímenes de los buenos funcionarios de la procuración de justicia no continúen impunes.

j) Involucramiento de organizaciones sociales serias en apoyo a las procuradurías en algunos aspectos de sus responsabilidades, como en la prevención del delito, específicamente de aquellos contra la salud, y las organizaciones no-gubernamentales de derechos humanos, en lo relativo a esta materia.

k) Reconocimiento social al trabajo policial bien realizado. Que los hijos de los policías no sientan vergüenza por la labor de sus padres. Policías bien integrados a su entorno social garantizan que involucrarse en la corrupción sea más difícil y costoso.

l) Fomento de principios morales laicos en la profesión jurídica. Se necesitan colegios de abogados, serios y responsables, que vigilen el desempeño ético de sus agremiados.

\section{RECAPITULACIÓN}

Reitero e insisto en algunas ideas expuestas en el ensayo, que me han preocupado desde hace muchos años:

1. La procuración de justicia es una función tan importante para el ser humano como la impartición de justicia. No obstante, a la primera se le ha me- 
nospreciado enormemente en casi todos los países del mundo, colocándola como parte del poder ejecutivo y limitando, por consecuencia, su independencia. La procuración de justicia es una labor técnica que debe estar alejada de la política y de la razón de Estado; quienes desempeñan esa delicada función deben gozar de garantías similares a las de un juez.

2. A partir de la segunda posguerra mundial, existen avances en asegurar la independencia de los agentes de la procuración de justicia y su total compatibilidad con el respeto a los derechos humanos, tal y como sucede en Alemania e Italia. Sin embargo, incluso esos sistemas son sujetos a cuestionamientos. El tema de la procuración de justicia constituye uno de los grandes debates actuales del Derecho Constitucional y del Penal.

3. En México, los problemas de la procuración de justicia se agudizan gravemente por la situación que guarda la moral pública, la cual se ve asolada por una quinteta de la muerte: poder, dinero, corrupción, impunidad y mentiras, así como por el avance del crimen organizado.

4. En el análisis que realicé sobre la moral pública en nuestro país en el año 2000, resalté como una de sus causas la existencia de un partido hegemónico durante siete décadas. Después de contemplar lo acontecido en el sexenio 2000-2006, durante esos años de la alternancia en el poder, en los cuales la quinteta de la muerte permaneció con igual o mayor vigor que antes, concluyo que esos males son más profundos y más arraigados en nuestra sociedad de lo que habia considerado.

5. En la problemática de la procuración de justicia debe otorgarse más y especial cuidado al factor humano, el que corresponde en buena parte al estado de la sociedad. Como bien dice Andrés de la Oliva, no podemos conformarnos con que el elemento humano de la justicia sólo refleje el ambiente social, sino que lo debe liderar y liderarlo ejemplarmente.

6. Las calidades que el procurador debe poseer — honestidad, capacidad y responsabilidad-permean a todos los servidores públicos de la dependencia. Es decir, cuando se conoce que se cuenta con un procurador con esas cualidades, los actos de corrupción, violaciones legales y a los derechos humanos, e irresponsabilidades disminuyen notablemente. Cuando el procurador no posee esas cualidades, la procuración de justicia tiende a convertirse en un enjambre de complicidades.

7. Desde luego, las cualidades y valores que destaco que deben adornar a los procuradores, son los mismos que deben poseer especialmente los altos funcionarios de la dependencia y, en general, todos aquellos que colaboran en la delicada función de la procuración de justicia, aunque el procurador es el líder y es hacia quien se dirigen todas las miradas en el organismo. El procurador tiene 
una responsabilidad especialmente delicada, y si no la cumple adecuadamente, a él hay que aplicarle la ley respectiva.

8. En consecuencia, es indispensable que el personal que labora en las procuradurías sea el idóneo y adecuado, y conseguirlo es posible. Al respecto, en este ensayo señalo algunas ideas, desde la manera del nombramiento, el establecimiento de una verdadera carrera de agente del ministerio público y de la policía hasta la creación de un sistema de estímulos sociales y económicos.

9. El estado actual de la procuración de justicia, la criminalidad y la inseguridad en nuestro país flagela gravemente a la sociedad, la aflige y la agravia.

Es obvio que la mayor responsabilidad de este desastre nacional corresponde a los tres niveles de gobierno, en particular a las procuradurías de justicia y a los cuerpos de seguridad. No obstante, la responsabilidad que en dicho desastre corresponde a la sociedad no es menor, debido a diversas razones; enuncio algunas tales como: indiferencia ante la impunidad de los homicidios de buenos y honestos procuradores y altos funcionarios de las procuradurías; aceptación social de ex-funcionarios corruptos y de delincuentes de calibre como grandes señores, debido a su inmensa fortuna; la actuación de organizaciones sociales y nogubernamentales por fobias, filias e ideologías; el papel que desempeñan algunos medios de comunicación; el alto grado de tolerancia a la impunidad, la corrupción y la mentira; el desamparo legal y social a buenos ex-funcionarios de procuración de justicia.

10. La procuración de justicia en México no va a mejorar sensiblemente si la sociedad no se involucra en el problema y modifica varias de sus actitudes e indiferencias. La sociedad organizada mucho puede lograr, comenzando por exigir corrupción cero, impunidad cero, no dejándose engañar y colocando a cada persona en el lugar social que merece. Es decir, no considerando al delincuente, sea quien sea y por la razón que sea, como un gran señor.

Ciudad Universitaria, D. F., marzo de 2008. 